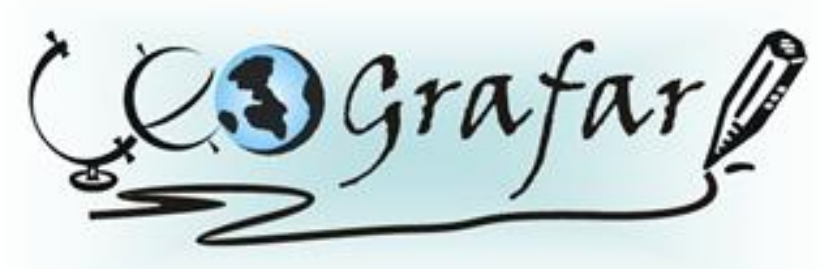

Revista Eletrônica do Programa de Pós-Graduação em Geografla - UFPR

\title{
MOBILIDADE SOCIAL E QUESTÃO TERRITORIAL EM MARINGÁ - PR: O CASO DOS MORADORES DO BAIRRO SANTA FELICIDADE ${ }^{1}$
}

\author{
ALTAIR APARECIDO GALVÃO ${ }^{2}$ \\ MÁRCIO MENDES ROCHA ${ }^{3}$
}

\begin{abstract}
Resumo: Pretendemos, por meio deste trabalho, contribuir na discussão da mobilidade social e da questão territorial, especificamente dos moradores do Conjunto Residencial Santa Felicidade. Para tanto, propusemo-nos a analisar a trajetória desses maringaenses, desde sua saída de áreas irregulares da periferia urbana da cidade, no final dos anos 1970, sua transferência para um distante bairro da zona sul, conhecido na época também como Profilurb, até a atualidade, quando, na ótica da elite local, se transformaram em um problema para o desenvolvimento daquela região. Nesse tempo, através de luta árdua, seus moradores construíram suas casas e consolidaram seus vínculos de vizinhança e amizade em condições adversas. O poder público municipal está implantando uma proposta de intervenção urbana, através do Programa de Aceleração do Crescimento (PAC), em Maringá. Esse projeto prevê para o Bairro Santa Felicidade, a transferência de 129 famílias para outros lugares, o que corresponde a liberação de 82 terrenos - atualmente o bairro tem 294 residências e 333 famílias. Em meio à complexidade das condições de mobilidade e da imobilidade, valorizamos como fonte de reflexão as pesquisas efetuadas por Caniato, em 1986 e pelo Observatório das Metrópoles -Núcleo de Maringá, em fevereiro de 2008.
\end{abstract}

Palavras-chave: mobilidade social; território urbano; ZEIS; Santa Felicidade.

Abstract: We intend to contribute with the discussion of the social mobility and the territorial matter, specificaly of the residents of Santa Felicidade house complex. For that to happen, we proposed to analyze the path of these citzens, since their departure from irregular áreas of Maringá's suburbs, in the late seventies, their transfer to a distant neighborhood of southern zone, known as Profilurb, until today, when the local elite point of view they became a problem to the development of that region. In this period, through their struggle, the residents built their houses and consolidated their neighborhood bonds and friendship in adverse conditions. City public power is making a proposal of urban intervention, through the Growth Acceleration Program (PAC), in Maringá. This Project predicts to Santa Felicidade district the decrease of 82 lots and the transfer of 129 families to other places. Nowadays the neighborghood has 294 houses and 333 families. In the middle of the complexity of mobility and non mobility conditions, we valued as source of reflection the researches made by Caniato in 1986 and by the Metropolis Observatory - Maringá Nucleus, in february of 2008.

Keywords: social mobility; territorial matter; citzenship; Santa Felicidade.

1 Este artigo é produto das reflexões realizadas na disciplina "Estudos Populacionais e Desenvolvimento Regional", sob a responsabilidade do Prof. Dr. Márcio Mendes Rocha, junto ao Programa de Pós-Graduação em Geografia da UEM - Universidade Estadual de Maringá.

${ }^{2}$ Cientista Social (bacharelado e licenciatura). Mestre e Doutorando em Geografia pela Universidade Estadual de Maringá - UEM. Pesquisador do Observatório das Metrópoles - RMM. E-mail: aapgalvao@hotmail.com

${ }^{3}$ Doutor em Geografia (Geografia Humana) pela Universidade de São Paulo, Brasil(1999). PósDoutor pela Universidade Estadual Paulista Júlio de Mesquita Filho, Brasil(2005). Prof. Associado da Universidade Estadual de Maringá. Coordenador do NEMO (Núcleo de Estudos de Mobilidade e Mobilização) e do Núcleo de Economia Solidária - NES - UEM de Maringá. E-mail: mmrocha@uem.br 


\title{
INTRODUÇÃO
}

\begin{abstract}
A cidade aparece como um todo no qual nenhum desejo é desperdiçado e do qual você faz parte, e, uma vez que aqui se goza tudo o que não se goza em outros lugares, não resta nada além de residir nesse desejo e se satisfazer.

Ítalo Calvino
\end{abstract}

Diante dos últimos acontecimentos envolvendo a implementação dos recursos do PAC - Programa de Aceleração do Crescimento - em Maringá, volta aos noticiários o perene drama dos moradores do Conjunto Residencial Santa Felicidade. Esses cidadãos são remanescentes da reurbanização promovida pelo poder público local na segunda metade da década de 1970, removidos que foram de 14 favelas que existiam na periferia urbana da cidade, para casas construídas pelo município, em bairro periférico da zona sul, denominado à época de Profilurb Programa de Financiamento de Lotes Urbanizados, através do qual foram edificadas as 30 primeiras casas que a população removida ocupou e se implantou a infraestrutura do bairro. No entanto, conforme Caniato (1986), após dez anos dessa transferência, as 30 famílias inicialmente assentadas, não receberam do poder público o diploma legal de propriedade definitiva dos imóveis, nem tampouco Ihes foram oferecidos os diferentes serviços e benfeitorias urbanas a que todos os cidadãos de outros bairros da cidade recebem normalmente. Atualmente, com mais de 31 anos de existência, o Conjunto Residencial Santa Felicidade (Figura 1) está situado em região considerada nobre, cercado por mansões, condomínios de luxo e um Centro Universitário, o que o transforma em uma espécie de "cancro", na visão dos promotores imobiliários e dos atuais ocupantes do poder público municipal. Nesse tempo, através de luta árdua, seus moradores construíram suas casas e consolidaram seus vínculos de vizinhança e amizade em condições adversas.

O projeto de reurbanização do Conjunto Residencial Santa Felicidade hoje está sendo implementado com recursos do PAC através do Programa de Requalificação Social ZEIS Santa Felicidade e será financiado pelo Ministério das Cidades, num custo de 25 milhões de reais, sendo que 5 milhões se referem à contrapartida do governo do estado e do município. O projeto prevê a transferência de 129 famílias para outros lugares, o que corresponde a liberação de 82 terrenos - atualmente o 
bairro tem 294 residências (Figura 2) e 333 famílias. O objetivo é ampliar o tamanho dos terrenos, que hoje têm $250 \mathrm{~m}^{2}$ e serão ampliados para tamanho que varia entre 300 a $350 \mathrm{~m}^{2}$, como se observa na Figura 3.

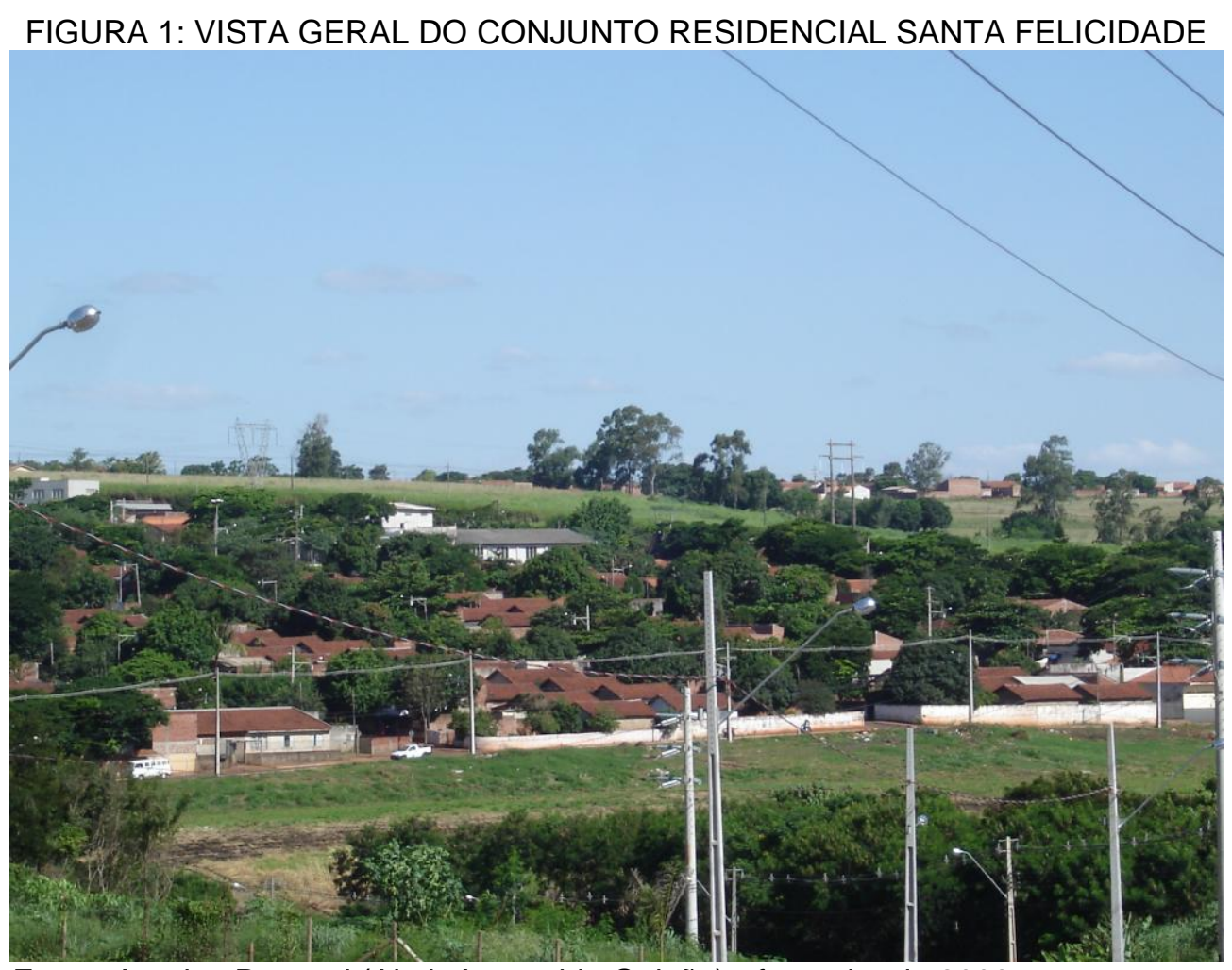

Fonte: Arquivo Pessoal (Altair Aparecido Galvão) - fevereiro de 2008.

FIGURA 2: IMAGEM DE SATÉLITE DO CONJUNTO RESIDENCIAL SANTA FELICIDADE

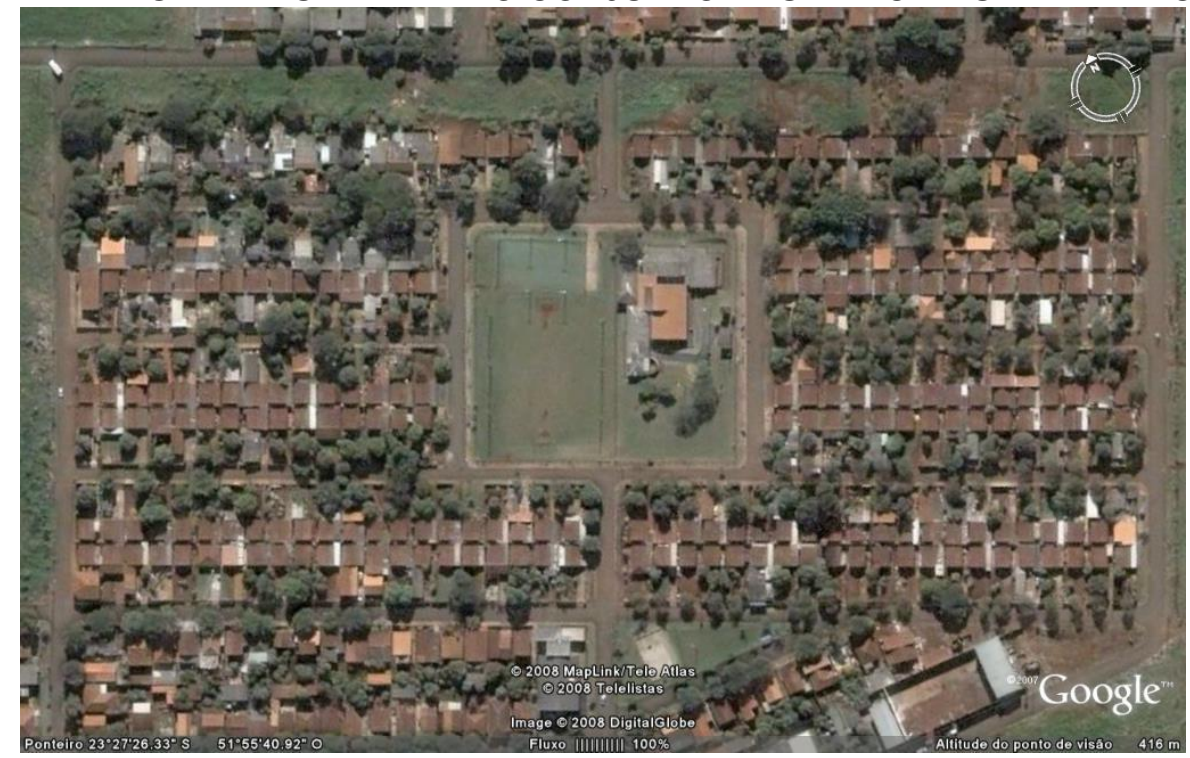

Fonte: 2008 Europa Technologies Image (Google Earth) 
O governo municipal, para justificar um processo de intervenção não debatido com a comunidade e baseado na remoção de pelo menos um terço das famílias, já no projeto enviado a Brasília, criminaliza os habitantes nos seguintes termos: "atualmente esta região é conhecida como muito carente e a mais violenta do município". Essa afirmativa vem confirmar a denúncia de Ermínia Maricato (1996), quando trata do conceito classista da sociedade, que liga a delinqüência às classes mais pobres. Essa sociedade, segundo essa autora, prioriza a defesa do patrimônio individual antes de priorizar, por exemplo, a integridade do trabalhador ou da criança.

Este artigo se propõe a analisar a trajetória dessas famílias - uma espécie de "calvário" -, desde a saída de áreas irregulares na então periferia urbana da cidade, em meados dos anos 1970, sua transferência para um distante bairro da zona sul da cidade, o Núcleo Habitacional Santa Felicidade, também conhecido no início por Profilurb, até a atualidade, quando, na visão da elite local, se transformaram em um problema para o desenvolvimento da região, ou seja, estão atrapalhando os interesses mercantis imobiliários dessa elite, que pretende abarcar esse espaço com o objetivo de satisfazer seus interesses capitalistas.

Utilizamos como técnica para a construção deste trabalho o levantamento histórico/bibliográfico e fontes constituídas por pesquisas realizadas pelo Observatório das Metrópoles - Núcleo de Maringá . 
FIGURA 3: PLANTA DA PROPOSTA DE AUMENTO DE TAMANHO DOS ATUAIS TERRENOS DO SANTA FELICIDADE - 2008

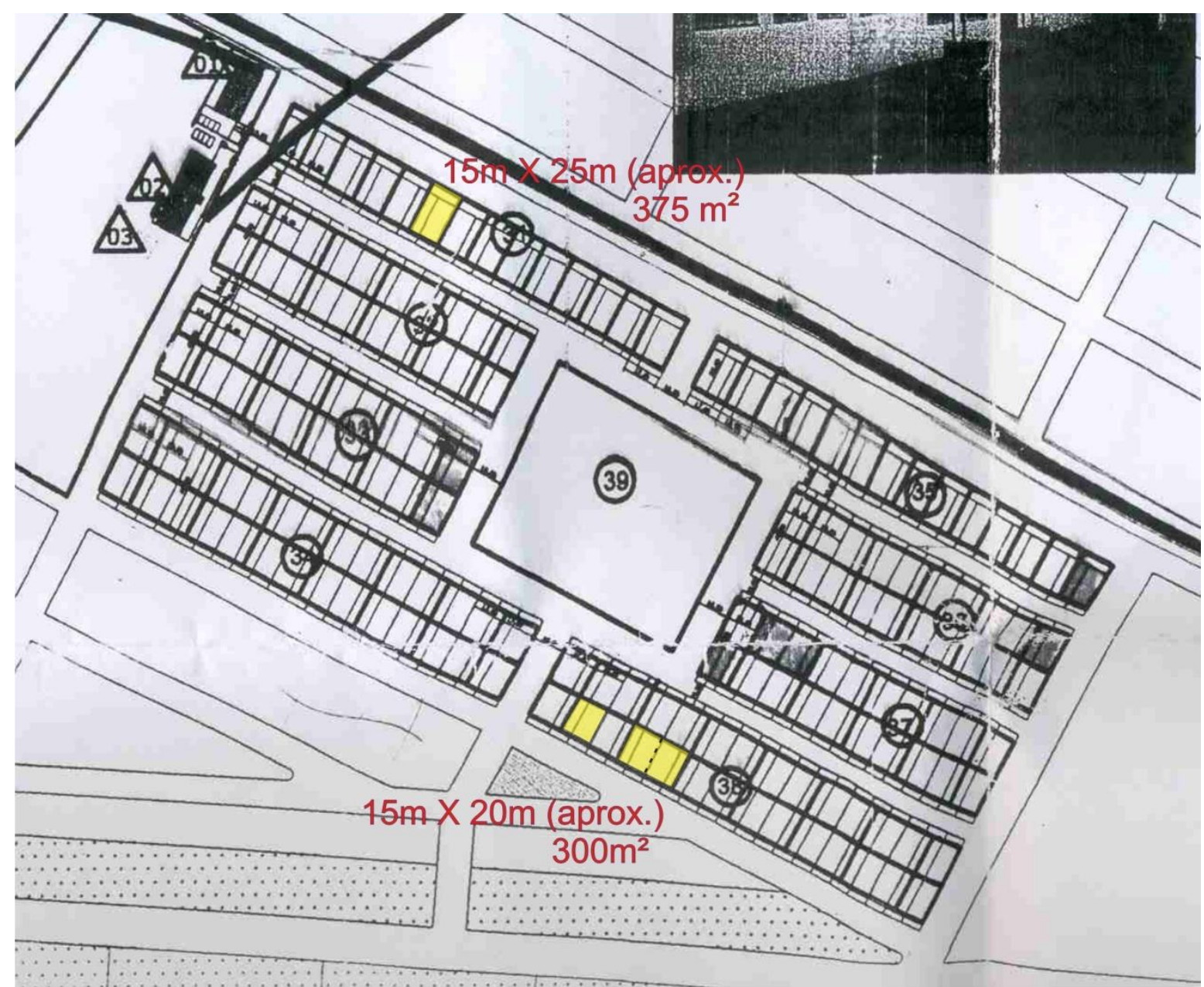

Fonte: Observatório das Metrópoles - Núcleo Região Metropolitana de Maringá-UEM

\section{Quadro síntese da proposta}

- $\quad 28$ terrenos de $15 \mathrm{~m} \times 25 \mathrm{~m}\left(375 \mathrm{~m}^{2}\right)$ aprox.

- 136 terrenos de $15 \mathrm{~m} \times 20 \mathrm{~m}\left(300 \mathrm{~m}^{2}\right)$ aprox.

- TOTAL: 164 terrenos

- $\quad$ Existentes: 246

- $\quad 82$ terrenos removidos

- Vias: caixa de rua $=5 \mathrm{~m} /$ passeios $=1,40 \mathrm{~m}$ 


\title{
DE FAVELADO A PROPRIETÁRIO: O SONHO DA CIDADANIA
}

\author{
Essas pessoas, de todo estado e de todas as \\ classes, não são todas elas homens possuindo \\ as mesmas capacidades, o mesmo interesse \\ na busca da felicidade? \\ Henri Lefebvre
}

Maringá, com uma população de 325.968 habitantes $^{4}$, localizada na região norte central do Estado do Paraná , a $428 \mathrm{Km}$ de Curitiba (Figura 4), é constantemente associada a uma imagem que a coloca entre as melhores cidades do país, quanto à qualidade de vida. Em meados da década de 1990 foi denominada de "Dallas Brasileira", graças à propagada potencialidade econômica de seus moradores e na atualidade está sendo chamada de "Amsterdã", em conseqüência da baixa taxa de homicídios ${ }^{5}$. Sendo projetada ${ }^{6}$ com amplas avenidas e espaços verdes, com bosques e parques, além de muitas praças, com comércio intenso e agroindústria dinâmica, a cidade, desde seu início carregou a vocação para ser o pólo regional (MENDES; GRZEGORCZYK, 2003, p.90). Outro motivo de orgulho para os maringaenses é o fato de a cidade não possuir favelas ou áreas de ocupação irregular.

Mas essa aparente harmonia urbana nem sempre foi observada em Maringá. Até meados da década de 1970, apesar de ter constituído a paisagem da cidade,

"a favela foi subtraída, compondo um processo de segregação residencial balizada por uma hierarquização social, que determinou um espaço de moradia aos pobres, não circunscrito aos espaços onde as favelas se localizavam, próximos às áreas centrais" (RODRIGUES, 2004, p.233).

\footnotetext{
${ }^{4}$ Estimativa populacional para 2007. Fonte: IBGE.

${ }^{5}$ A comparação com Amsterdã, capital da Holanda, tem como causa a matéria publicada na Revista Veja de 23 de julho de 2008, que trata de pesquisa realizada em 5.564 municípios brasileiros. Esta pesquisa selecionou 40 cidades que possuem indicadores sociais de países ricos. Dentre esses municípios, segundo a pesquisa, Maringá é a que tem o menor índice de homicídios (7,9 para cada 100.000 habitantes/ano).

${ }^{6}$ Maringá foi projetada por Jorge Macedo Vieira (1894-1978), paulista, Engenheiro Civil formado pela Escola Politécnica de São Paulo (1917), que já constava em seu currículo projetos como o do Jardim Paulista, da cidade de São Paulo e de Águas de São Pedro, no interior do Estado de São Paulo, foi contratado pela CMNP para desenvolver o projeto de Maringá. Vale destacar que Vieira nunca veio à Maringá.
} 
FIGURA 4: LOCALIZAÇÃO DA CIDADE DE MARINGÁ - PR - BRASIL
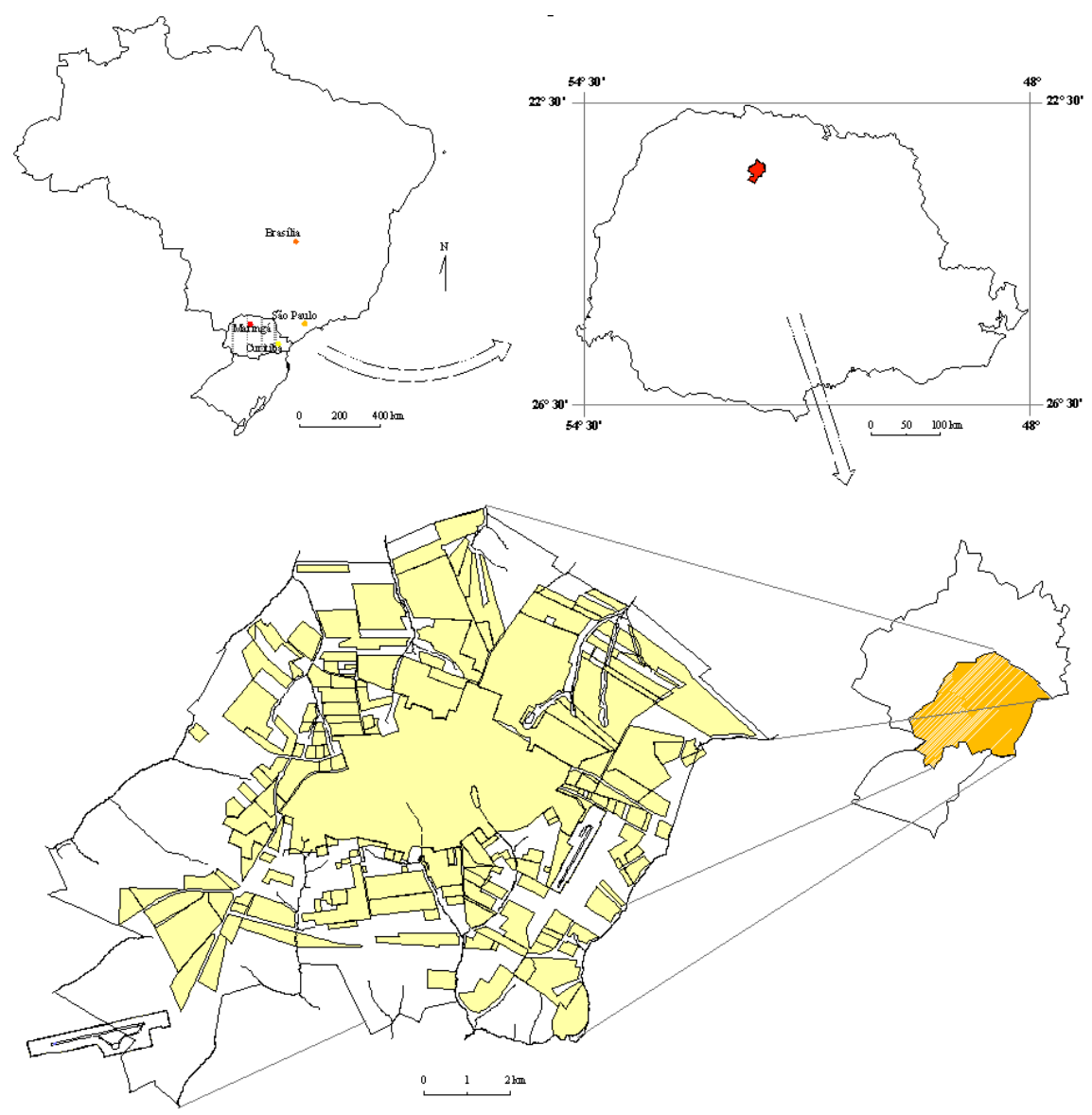

Fonte: PARANÁ, 2004; Prefeitura Municipal de Maringá, 2000.

Adaptação: Altair Aparecido Galvão, 2006.

Em 11 de dezembro de 1975, o município de Maringá cria a lei 11/75, que visa difundir sua política de assistência social no campo da cooperação habitacional e institui o Programa Social de Desfavelamento Municipal, sendo que a finalidade era "proporcionar à Família Maringaense, cujos rendimentos auferidos estejam abaixo dos valores mínimos estabelecidos pelo programa habitacional do $\mathrm{BNH}$, através de seus órgãos cooperadores e promotores, a oportunidade de virem possuir casa própria" (CANIATO, 1986, p.15). A meta principal desse programa foi criar o Núcleo Habitacional Santa Felicidade, financiado pelo BNH - Banco Nacional de Habitação / PROFILURB - Programa de Financiamento de Lotes Urbanizados -, situado na Gleba Pingüim, cujo plano global consistia em implantar nesse local: iluminação pública, rede de água pluvial e esgoto sanitário, água potável, praça pública urbanizada, ponto de ônibus coberto, ruas asfaltadas, centro social etc. Para tanto, o 
município delegou competência para que a Fundação de Desenvolvimento Social de Maringá, criada pela Lei Municipal № 1122/76, de 04/05/1976, fosse o agente promotor do Programa Social de Desfavelamento Municipal.

Além de proporcionar moradia decente à população mais pobre da cidade, o objetivo do poder municipal era acabar com a paisagem degradante que os barracos ocasionavam ao ideário de "cidade verde", "cidade canção", "cidade modelo" e etc. que Maringá já ostentava na época. Para tanto, a Fundação de Desenvolvimento Social de Maringá promoveu o levantamento dos favelados e das pessoas que residiam em condições precárias, conseguindo cadastrar 585 famílias.

Iniciou, também, o fechamento da maior favela da cidade, que chegou a ter mais de 300 (trezentos) ranchos - Favela do Cemitério providenciando a numeração dos barracos e, através da vigilância de guardas municipais, passou a impedir a construção de novos barracos, assim como consertos que o favelado precisasse fazer no rancho para ele poder continuar morando (CANIATO, 1986, P.16).

Era prefeito de Maringá nesse período o Sr. Silvio de Magalhães Barros, que, após fazer a urbanização dos 280 lotes, iniciou a construção das casas-embrião e fez questão de inaugurar as 30 primeiras unidades construídas, mas não acabadas, no término de sua gestão. Assim, no dia 28/01/1977, esses mutuários assinaram os contratos de cessão das casas, sendo que as chaves thes foram entregues em 29/01/1977, dia de inauguração oficial do Bairro Santa Felicidade - Profilurb.

O novo prefeito empossado em 01/02/1977, o Sr. João Paulino Vieira Filho, abandonou o projeto Profilurb, mas em função das reclamações dos proprietários dos imóveis onde se encontrava a Favela do Cemitério, promoveu a expulsão dos favelados e a derrubada dos barracos, colocando as pessoas com seus parcos pertences em caminhões e deixando-as pelas estradas e municípios vizinhos (CANIATO, 1986, p.17).

Além daqueles ex-favelados que conseguiram colocação em Santa felicidade, alguns foram removidos "para Sarandi (em barracões improvisados, dos quais até hoje ainda há 134 barracos remanescentes, no chamado "Mutirão"), para a Vila Guadiana, em Mandaguaçu, dentre outros lugares" (RODRIGUES, 2008, p.7) 
Devido à cobrança da imprensa, de prefeitos de cidades vizinhas (onde os favelados iam procurar abrigo) e de alguns maringaenses, o prefeito João Paulino se viu obrigado a criar uma comissão especial com a finalidade de solucionar o problema dos moradores da favela do cemitério, indenizando alguns, cadastrando outros, com a finalidade de qualificá-los no projeto Profilurb. Poucos desses favelados conseguiram chegar ao "sonho" de morar em Santa Felicidade, ou seja, ser uma das 246 famílias a habitar o novo bairro. Na realidade, as unidades desse novo bairro, apesar de serem construídas dentro de uma concepção humilde, foram bastante utilizadas como moeda de troca no processo eleitoral, contemplando cabos eleitorais e amigos de políticos que queriam retribuir algum favor, assim como ocorre costumeiramente em situações similares a esta, num processo de clientelismo explícito. Quando da inscrição para que as famílias se candidatassem a uma das unidades habitacionais, as exigências impostas aos favelados eram sempre mais rígidas:

Aparece nítida a discriminação dos favelados quando da exigência de documentos a serem apresentados à Fundação para a permissão de mudança para as casas do Profilurb. Embora a "Análise Diagnóstica do Núcleo Habitacional Santa Felicidade - Profilurb", feita pela Fundação de Desenvolvimento Social de Maringá em outubro de 1978, tivesse declarado que os "Critérios para a aquisição de casa própria" eram:

Ser morador do município;

Apresentar atestado de boa conduta;

Apresentar declaração assinada por dois ex-vizinhos;

Ter trabalho efetivo;

Perceber uma renda mensal inferior a um salário mínimo;

Ser casado e possuir filhos.

Pode-se constatar, nas pastas individuais de cada morador, arquivadas na Fundação, que os indicados por "Instituições Assistenciais" da cidade foram privilegiados para a cessão das casas - das 30 casas do Profilurb, foram ocupadas apenas 13 por moradores da Favela do Cemitério, a qual era, na época, a maior favela da cidade e de onde haviam sido classificados, inicialmente, para o Programa Profilurb, 59 famílias. Não só a nível quantitativo, houve também discriminação dos moradores da Favela do Cemitério no que se refere à apresentação de documentos à Fundação por ocasião das assinaturas dos Contratos de Comodato. Assim, eles foram obrigados a apresentar à Fundação atestados de "Boa Conduta" e "Nada Consta", retirados na delegacia e varas criminais da cidade, enquanto que para os assistidos por aquelas Instituições de Caridade bastava, apenas, uma declaração dos presidentes 
dessas entidades, encaminhando os candidatos às casas do Profilurb à Fundação (CANIATO, 1986, p.20).

Quando Caniato completou sua pesquisa no ano de 1986, os moradores do Bairro Santa Felicidade ainda não tinham em mãos os contratos definitivos de compra das casas, e nem mesmo os contratos de comodato que assinaram com a Prefeitura. Assim, esses moradores passaram esse período de tempo na insegurança de serem ou não expulsos do local. Essa situação de insegurança, no entanto, serviu para que eles se organizassem e criassem sua Associação de Bairro, que possibilitou a unidade de luta contra o poder local para serem respeitados em sua cidadania.

Atualmente, após mais de 31 anos de sua inauguração, o Núcleo Habitacional Santa Felicidade é um bairro consolidado (Figura 5), abrigando a terceira geração daqueles primeiros moradores, pois no trabalho de campo que realizamos nos meses de fevereiro e março de 2008, pudemos encontrar alguns daqueles pioneiros que se mudaram para o local em 1977, com seus filhos - alguns destes nascidos no Santa Felicidade -, e netos - estes sim, todos nascidos ali.

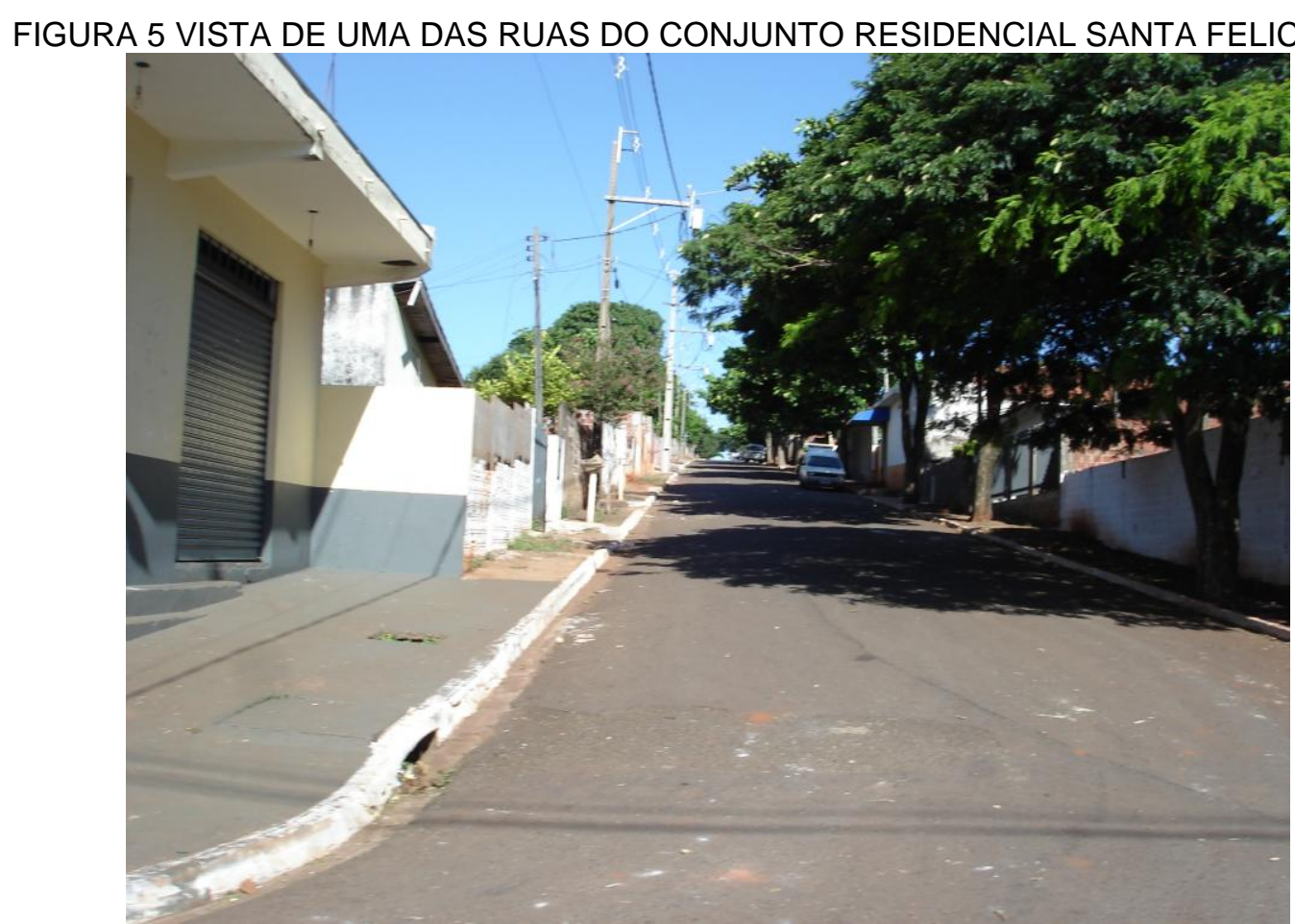

Fonte: Acervo pessoal (Altair Aparecido Galvão) - fevereiro de 2008. 


\section{MOBILIDADE SOCIAL E A QUESTÃO TERRITORIAL}

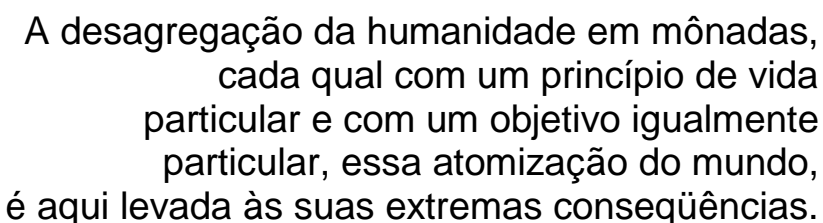

Friedrich Engels

A mobilidade social no Brasil tem sido objeto de estudos de sociólogos, cientistas políticos, economistas e geógrafos (PASTORE [1979], ROCHA [1998, 1999,], SCALON [1999], entre outros). E essa mobilidade social está intimamente ligada à questão territorial, pois é regra comum que a mudança de status social, tanto para cima, quanto para baixo, na pirâmide social, implique em locomoção física, podendo ser do campo para a cidade, de uma cidade para outra, ou mesmo de uma unidade residencial para outra, no mesmo município. O Brasil foi, há aproximadamente cinco décadas atrás, o país da miséria rural, onde a distância social não era medida pelo nível de renda, mas pelo modo de vida que se observava entre os moradores de um bairro de uma cidade qualquer e os da colônia de empregados de um sítio ou fazenda. Nesse espaço rural vivia a maior parte da população. Hoje, essa fatia pobre da população mudou-se para as cidades e uma boa parte dela enfrenta um cotidiano de dificuldades diferentes das que enfrentavam na zona rural, devido à falta de qualificação profissional e, principalmente, pela falta de um lugar decente para morar. A reconstituição histórica das diferentes formas de habitar tem sido objeto de estudo dos pesquisadores das diversas áreas das ciências humanas. Para a camada da população mais abastada, sobram possibilidades, pois o mercado imobiliário, sempre atento às tendências temporais, oferece desde apartamentos funcionais para aqueles que têm poder aquisitivo imediato ou acesso a financiamentos bancários, e também para os que podem pagar verdadeiras fortunas por imensos duplex em edifícios luxuosos, localizados nas vias mais importantes, ou mansões em bairros nobres, ou ainda residências cinematográficas em Condomínios Horizontais Fechados de bairros periféricos da cidade. "O sonho de consumo das classes mais abastadas é morar em espaços propícios à sua proteção. Assim, os que podem, encastelam-se em seus mundos, para o resto da população, resta a cidade real, em seu estado bruto" (GALVÃO, 
2007, p.62). Essa cidade em "estado bruto" é representada por residências localizadas em bairros distantes do centro das cidades, quase sempre sem equipamentos urbanos adequados (asfalto, escolas, creches, centros de saúde, transporte coletivo, áreas de recreação, esgoto sanitário, etc.), ou mesmo por áreas de ocupações irregulares, invadidas e deterioradas, constituídas por ranchos e barracos, mais comumente conhecidas como favelas. Sobre este tema, observemos as palavras do geógrafo Roberto Lobato Corrêa:

É na produção da favela, em terrenos públicos ou privados invadidos, que os grupos sociais excluídos tornam-se, efetivamente, agentes moderadores, produzindo seu próprio espaço, na maioria dos casos independentemente e a despeito de outros agentes. A produção deste espaço é, antes de mais nada, uma forma de resistência e, ao mesmo tempo, uma estratégia de sobrevivência. Resistência e sobrevivência às adversidades impostas aos grupos sociais recémexpulsos do campo ou proveniente de áreas submetidas às operações de renovação, que lutam por direto à cidade (CORRÊA, 2004, p.30).

Zaluar; Alvito, que pesquisaram as favelas do Rio de Janeiro, explicam que:

A favela ficou também registrada oficialmente como a área de habitação irregularmente construída, sem arruamentos, sem plano urbano, sem esgotos, sem água, sem luz. Dessa precariedade urbana, resultado da pobreza de seus habitantes e do descaso do poder público, surgiram as imagens que fizeram da favela o lugar da carência, da falta, do vazio a ser preenchido pelos sentimentos humanitários, do perigo a ser erradicado pelas estratégias políticas que fizeram do favelado um bode expiatório dos problemas da cidade, o "outro", distinto do morador civilizado da primeira metrópole que o Brasil teve (ZALUAR; ALVITO, 1998, p.7-8).

Um aspecto bastante peculiar às favelas e aos bairros periféricos em geral é o de um eterno canteiro de obras. Esta característica é causada pela falta de recursos dos moradores, que quase nunca conseguem terminar a construção de suas unidades residenciais que, graças a seu formato evolutivo, tem a possibilidade de transformação, ou mesmo substituição por similar em material de maior durabilidade ou de qualidade superior. É bastante comum mutirões em fins de semana ou feriados, quando um grupo de amigos e vizinhos se reúnem para "concretar uma 
laje" ou erguer paredes da casa de um morador que, como agradecimento, providencia um churrasco ou outro tipo de agrado aos participantes. Outra particularidade dessas modalidades habitacionais é a heterogeneidade, pois refletem a diversidade de renda de seus moradores, apresentando, assim, tamanhos, materiais e acabamentos diversificados.

Quanto ao aspecto urbanístico, ao ser vistos de longe, um bairro periférico ou mesmo uma favela, podem ser confundidos com outro bairro qualquer, mas quando olhamos mais atentamente, podemos notar as peculiaridades, como aponta Suzana Pasternak:

Ao longe, a casa favelada confunde-se com a do anel periférico em geral: o mesmo cinzento do bloco e da laje, a mesma aparência de eterna construção com o vermelho dos tijolos de vedação galgando mais um andar. Um olhar de perto, entretanto, capta sua especificidade: casas menores, densidade domiciliar maior, saneamento precário, lixo amontoado, caminhos tortuosos e estreitos, ausência de áreas coletivas, situação em áreas de fundo de vale ou grande declividade. Em relação ao desenho urbano, densidades demográficas muito mais altas que as do entorno (PASTERNAK, 2004, p.53)

É notório que as cidades brasileiras expressam de forma bastante clara o perverso modelo de desigualdade social do país. Mesmo tendo melhorado nas duas últimas décadas - de acordo com o relatório da ONU, o Brasil atingiu em 2007 o Índice de Desenvolvimento Humano $(\mathrm{IDH})^{7}$ de 0,800 , em uma escala de 0 a 1 (países com índice inferior a 0,800 são considerados de "médio desenvolvimento humano", categoria na qual o Brasil figurava desde 1990, quando o PNUD começou a divulgar o ranking) -, o país tem uma das piores distribuições de renda do planeta, só perdendo neste aspecto para Serra Leoa.

O município de Maringá não foge a esta regra, mas graças aos discursos da imprensa local e de políticos - especialmente em época de eleições -, acaba por criar uma espécie de "redoma" protetora, ou, conforme as palavras de Tonella; Rodrigues, uma "cerca invisível":

\footnotetext{
${ }^{7}$ IDH - Índice de Desenvolvimento Humano, é parte integrante do Relatório de Desenvolvimento Humano produzido pelo PNUD - Programa das Nações Unidas para o Desenvolvimento Humano, abrange 177 países, tendo esse índice a finalidade de ser um indicador de qualidade de vida das populações. Foi desenvolvido em 1990 pelo economista paquistanês Mahbub Haq, esse relatório é emitido desde 1993.
} 
Além dos dados objetivos que marcam as diferenças, a cultura política reafirma o espaço local, criando uma cerca invisível entre os municípios da região metropolitana, especialmente em relação aos contíguos. Em época eleitoral, esse discurso aparece com toda energia, reforçado pela imprensa e por candidatos a cargos legislativos. A cerca invisível se materializa na visão da população da sede regional ao considerar que todos os pedintes, as crianças e os malabaristas nos semáforos, sejam moradores das cidades vizinhas (TONELLA; RODRIGUES, 2003, p.10).

Nesta perspectiva, convencionou-se no imaginário da população maringaense a idéia de que os pobres que circulam pela cidade são dos municípios contíguos. $\mathrm{E}$ esses pobres - na visão da imprensa, das autoridades e da população locais -, incomodam, pois chegam à procura de atendimento médico nos hospitais públicos e, especialmente, de alguma ocupação que lhes dê algum rendimento, o que não conseguem em sua cidade de origem. Esses migrantes, por não possuírem qualificação profissional, não conseguem um emprego formal e acabam entrando na marginalidade, cuidando de carros, pedindo esmolas, furtando, prostituindo-se etc. Em contrapartida, na mesma proporção, chegam à Maringá, oriundos dessas mesmas cidades contíguas, os representantes das classes média e rica, com 0 objetivo de consumir nos estabelecimentos comerciais, freqüentar as escolas, ou usufruir da rede de clínicas e hospitais particulares especializados. Esta última situação é vista como fator positivo, pois capta recursos financeiros, fortalecendo o comércio local e ajudando a reafirmar a condição de Maringá como cidade pólo regional.

Assim, podemos observar que a complexidade das condições de mobilidade evidencia que o estudo e a definição de migrações, unicamente como deslocamento no espaço, não conseguem explicar esse fenômeno. A mobilidade física, condicionada por uma mobilidade forçada pela lógica do modo de produção capitalista, estabelece demandas criadas pelo próprio sistema, onde os distanciamentos sociais são partes constitutivas das relações socioespaciais. 


\title{
MORADORES DO CONJUNTO HABITACIONAL SANTA FELICIDADE: DE ONDE VIERAM? PARA ONDE VÃO?
}

\author{
A cidade real não passa de \\ referência longínqua e abstrata. \\ Ermínia Maricato
}

No caso específico do nosso objeto de estudo, os moradores do Conjunto Residencial Santa Felicidade, notamos que existe por parte do Estado capitalista, representado pelo poder público municipal, uma política segregacionista que, em última análise, tem representado um desenvolvimento à custa de deslocamentos forçados. Os fatores que determinam esses deslocamentos advêm dos mais diversos ramos das ciências humanas. Observamos que..."a mobilidade da força de trabalho na economia, a mobilidade social na sociologia, a mobilidade geográfica na geografia, além de outros tantos usos, como mobilidade forçada, mobilidade induzida, mobilidade física" (ROCHA, 1999, p.153). Essas diversas ordens de mobilidade em diferentes ramos da ciência humana, podem ocasionar redundâncias conceituais. Assim,

[...] A problemática da mobilidade se coloca hoje como preocupação emergente para as investigações sociais. Os deslocamentos humanos são determinados por uma série de fatores, econômicos, étnicos, raciais, afetivos, ideológicos; enfim, os motivos que fazem as pessoas se deslocarem são complexos e, consequentemente, devem ser investigados a partir de um constructo teórico compatível com tal complexidade (ROCHA, 1999, p.153).

Em Maringá, esses deslocamentos aconteceram, em um primeiro momento, quando os moradores foram transferidos dos barracos das 14 favelas para 0 Conjunto Residencial Santa Felicidade, na época localizado em uma região isolada do perímetro urbano da cidade, sem os equipamentos básicos; na atualidade, acontecem quando um projeto de reurbanização, financiado pelo Ministério das Cidades, prevê a transferência de 129 famílias para outros lugares ${ }^{8}$ (Figura 6), pois são vistos como um problema para o progresso da região, por ser a única camada

\footnotetext{
${ }^{8}$ Esses lugares são pequenas ZEIS (Zona Especial de Interesse Social) criadas especialmente para fazer uma espécie de "pulverização" dessas 129 famílias, espalhando-os por várias partes da cidade.
} 
pobre dentro de um contexto que comporta vários condomínios de luxo, um centro universitário particular e residências de médio e grande porte.

Um dos instrumentos usados pelo poder público para a remoção dos moradores do Conjunto Habitacional Santa Felicidade, foi a criação das ZEIS, distribuídas nas mais diversas regiões da cidade. Esse ato aconteceu no dia 8 de dezembro de 2005, quando foi aprovada a Lei Complementar ํㅜ 565, a partir da mensagem do Poder Executivo. O artigo 1 dessa Lei Complementar diz que as ZEIS são destinadas "a implantação de empreendimentos habitacionais de iniciativa exclusiva do Município de Maringá, com recursos próprios ou provenientes de termos de cooperação firmados com outros órgãos públicos financiadores, visando atender à população de baixa renda". (grifo nosso)

Porém, a Lei ํㅜ 7629, de 1ำ de agosto de 2007, que institui o Programa de Parceria com a Iniciativa Privada para a Implementação de Loteamentos de Interesse Social, em seu $2^{\circ}$ parágrafo do artigo $5^{\circ}$, afirma que "A implantação das ZEIS fica limitada à abrangência de no máximo 10\% da quantidade de imóveis do Município". Alguns autores consideram que esta é uma prática de segregação para com os mais pobres e é corriqueira em Maringá desde a sua fundação. Para Rodrigues (2008), essa limitação de no máximo 10\% de ZEIS no município contradiz o Plano Diretor, pois:

\footnotetext{
Isso contradiz aquilo que está garantido no PD como política de democratização do espaço urbano, pois, desta forma, há um limite para as áreas destinadas a empreendimentos de interesse social dentro do município Ou seja, reitera-se a antiga tradição maringaense de não agregar população de baixa renda em seu território. (RODRIGUES, 2008, p. 12)
}

Através dessa Lei, foram desafetadas do seu caráter público e transformadas em ZEIS as seguintes áreas de terras:

1) Data 01, da Quadra 224, do Jardim Atlanta;

2) Data 06, da Quadra 369, do Jardim Atlanta;

3) Data 25, da Quadra 214, do Jardim Botânico;

4) Data 01, da Quadra 29, do Jardim Diamante;

5) Data 01, da Quadra 20, do Jardim Diamante; 
6) Data 01, da Quadra 30, do Jardim Diamante;

7) Data 01, da Quadra 380, do Parque Residencial Ibirapuera;

8) Data 01, da Quadra 95, do Jardim Indaiá;

9) Data 06, da Quadra 94, do Jardim Indaiá;

10) Datas 02 e 03, da Quadra 176, do Jardim Kakogawa;

11) Data 01, da Quadra 112, do Jardim Licce;

12) Data 19, da Quadra 139, do Loteamento Madrid;

13) Data 26, da Quadra 82, do Loteamento Madrid;

14) Data 15, da Quadra 80, do Jardim dos Pássaros;

15) Quadra 74, do Conjunto Habitacional Paulino Carlos Filho;

16) Datas 04 e 05, da Quadra 414, do Jardim Paulista II;

17) Data 08, da Quadra 425, do Jardim Pinheiros III;

18) Datas 01, 01-A, 01-B, 01-C, 01-D, 01-E, 01-F, 01-G, 01-H, 01-I, 01-J, todas da Quadra 103, do Jardim Santa Rosa.

Foram somente transformadas em ZEIS as seguintes áreas de terras (Figura 5):

1) Quadra 93, do Jardim Dourado;

2) Data 01, da Quadra 93, Conjunto Habitacional Léa Leal;

3) Data 17, da Quadra 52, do Jardim Paris IV;

4) Data 06, da Quadra 97, do Parque Residencial Patrícia;

5) Lote 17, 18, 19, 20, 21, 22/66 remanescente, da Gleba Pingüim;

6) Lote $87-B / A$, da Gleba Ribeirão Morangueiro;

7) Lote $87-B / B$, da Gleba Ribeirão Morangueiro.

FIGURA 6: MAPA DAS ZONAS E ESPECIAIS DE INTERESSE SOCIAL (ZEIS) DE MARINGÁ - 2007

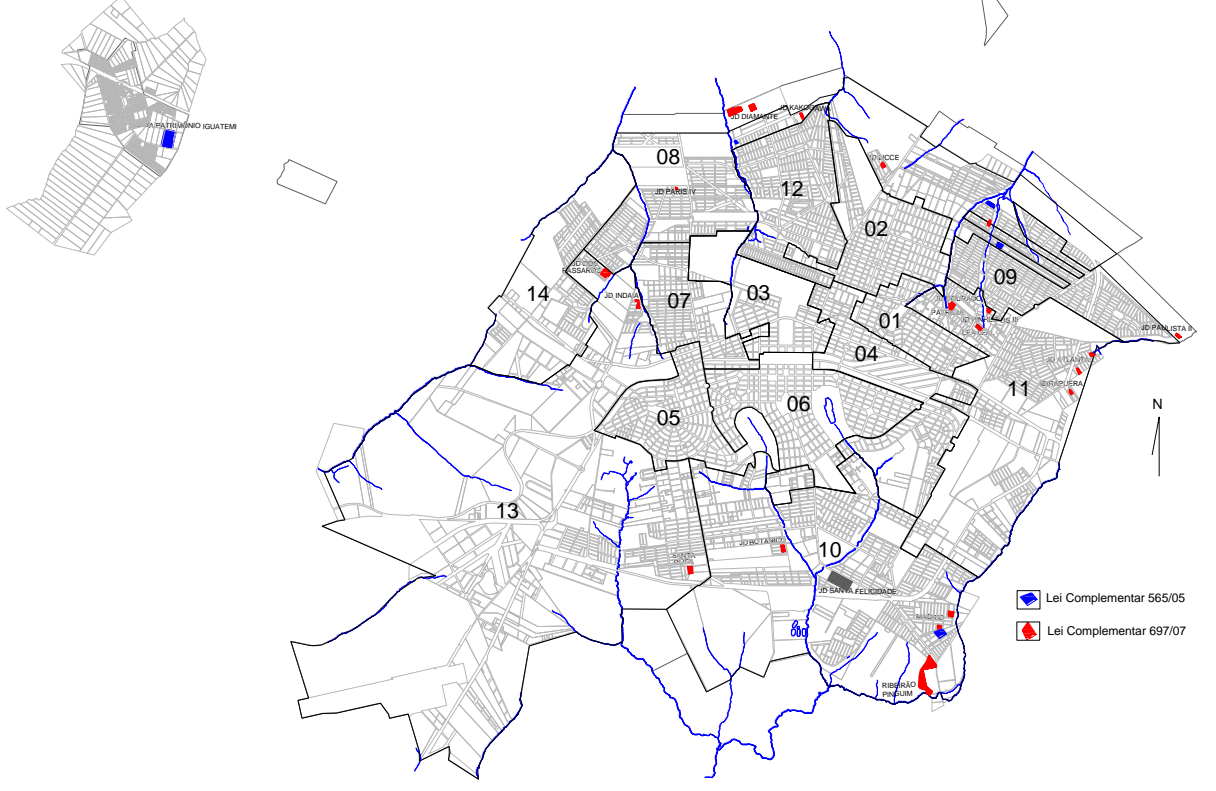

Observação: Três áreas da ZEIS 565/05 não foram mapeadas, devido à falta de localização nos mapas disponíveis (provável localização na área rural)

Fonte: Prefeitura Municipal de Maringá, 2007 /

Organização: Observatório das Metrópoles: RMM/ CCH/ UEM, 2008.

As reflexões contidas neste artigo foram baseadas em pesquisa de campo realizada pelo Observatório das Metrópoles - RMM. Assim, pretendemos, a partir da análise dos dados dessa pesquisa, contribuir na discussão sobre a mobilidade social 
e a questão territorial para "[...] ousar desafiar o que há por trás da famosa liberdade de ir e vir, instaurada como conquista fundamental e um dos mitos da sociedade burguesa" (VAINER, 1996, p.5).

SANTOS explica que o conceito de território é aquele que o considera peculiarmente ligado à sociedade e sem a qual este não tem sentido:

O território em si, para mim, não é um conceito. Ele só se torna um conceito utilizável para a análise social quando o consideramos a partir do seu uso, a partir do momento em que o pensamos juntamente com aqueles atores que dele se utilizam [...] (SANTOS, 2000, p.12).

Diferentemente de resultados obtidos por Caniato (1996), a nossa pesquisa, que aconteceu em fevereiro de 2008, quando o Conjunto Residencial Santa Felicidade completava 31 anos, nos mostrou que apenas 14,68 \% dos moradores atuais sempre moraram no local, ou seja, representam aquele grupo inicial, advindos das favelas. O restante dos entrevistados são oriundos de praticamente todas as AEDs (Áreas de Expansão Demográfica) da cidade e uns poucos $(8,71 \%)$ de cidades da região e especificamente de Sarandi e Paiçandu, como nos mostra a tabela 1.

Estes números, conseguidos através de nossa pesquisa, nos apresenta uma população vinda de várias partes da cidade de Maringá e região e é diferente do verificado no trabalho de Caniato (1986), pelo fato de que durante os 31 anos que consolidaram o Conjunto Residencial Santa Felicidade, várias etapas de construções aconteceram e resultaram na ocupação de todos os 246 lotes. Também aconteceu de alguns poucos transferirem seus direitos a outros, que residem até hoje no local. 
TABELA 1 - LOCAL (BAIRRO OU CIDADE) ONDE O RESPONDENTE À PESQUISA NO CONJUNTO HABITACIONAL SANTA FELICIDADE RESIDIA ANTERIORMENTE

\begin{tabular}{c|l|c|c}
\hline AED & \multicolumn{1}{|c|}{ Descrição } & Pessoas & $\%$ \\
\hline 6 & Zona 01, 02,03 e 04 & 39 & 17,89 \\
\hline & Sempre morou no bairro & 32 & 14,68 \\
\hline 4 & Zona 08 - Vila Santo Antônio & 24 & 11,01 \\
\hline 10 & Cidade Alta - Condomínios Verticais & 19 & 8,72 \\
\hline 11 & Liberdade - Aeroporto & 18 & 8,26 \\
\hline 7 & Av. Mandacaru - V. Santa Isabel & 15 & 6,88 \\
\hline & Outras Cidades do Paraná & 12 & 5,50 \\
\hline 2 & Jardim Alvorada & 11 & 5,05 \\
\hline 9 & Conj. Requião - Jd. Oásis & 8 & 3,67 \\
\hline & Zona Rural de Maringá & 6 & 2,75 \\
\hline & Outros Estados & 6 & 2,75 \\
\hline 19 & Sarandi - Linha do Trem & 5 & 2,29 \\
\hline 3 & Zona 07 - UEM & 4 & 1,83 \\
\hline 5 & Zona 05 - 06 & 4 & 1,83 \\
\hline 12 & Jd. Imperial - Pq. Das Grevíleas & 4 & 1,83 \\
\hline 1 & Vila Morangueira & 3 & 1,38 \\
\hline 8 & Contorno Norte & 2 & 0,92 \\
\hline & Outros Bairros de Maringá & 2 & 0,92 \\
\hline 14 & Olímpico & 1 & 0,46 \\
\hline 15 & Paiçandu & 1 & 0,46 \\
\hline 16 & Sarandi - Centro e Jd. Verão & 1 & 0,46 \\
\hline & Não respondeu & 218 & 0,46 \\
\hline & & 100 \\
\hline & & 1 & 019 \\
\hline
\end{tabular}

Fonte: Observatório da Metrópoles - RMM (fevereiro de 2008).

\section{CONSIDERAÇÕES FINAIS}

O padrão arquitetônico da cidade também segrega, separa, expulsa. Ana Fani Alessandri Carlos

A mobilidade social no Brasil tem sido objeto de estudo das mais diversas áreas das Ciências Humanas, em especial da Geografia, pois o tema está diretamente ligado à mobilidade espacial da população brasileira. A todos que se propõem a discutir o conceito de migração e território é necessário indagar se realmente existe uma questão migratória no Brasil e de que maneira ela se apresenta. Martins (1998) contesta os métodos do IBGE (Instituto Brasileiro de Geografia e Estatística), quando este considera migrante aquele indivíduo que nasce em um município e reside em outro. Para esse autor é um equívoco pensar a migração pura e simplesmente como um problema, pois praticamente a metade da população é migrante. Com efeito, quando um indivíduo ou mesmo uma família inteira migra de um local (município, estado ou país) para outro, em condições de igualdade ou de melhoria, não pode ser considerado um problema. Na maioria desses casos, há um acréscimo na qualidade de vida desses indivíduos. O problema 
da migração fica visível quando acontece a mobilidade forçada, especificamente na região em foco (Norte Central do Paraná) com o êxodo rural, onde

[...] a combinação temporal dos dois pressupostos básicos para a formação do trabalho assalariado, ou seja, a dissolução das relações com os instrumentos de trabalho, ocorrida de forma desigual, não necessariamente simultânea, comporta variações intermediárias nas diversas etapas e estágios históricos e produz espaços diferenciados (ROCHA, 1999, p.157).

Quando falamos em fluxos, pontos de partida e de chegada, retorno, tempo de duração, desejos e determinações históricas das famílias impactadas, necessário se faz observar as ações e situações que reproduzem relações sociais de superações, emancipações e fracassos. As contradições da mobilidade e imobilidade nos mostram histórias comuns que se expressam, não somente nas palavras dos envolvidos, mas também nas lágrimas e nos sofrimentos daqueles a quem não é concedido o direito do livre expressar da opinião.

Este artigo se propôs mostrar a trajetória dos moradores do Conjunto Habitacional Santa Felicidade, a partir da pesquisa de Caniato (1986) e do Monitoramento do Processo de Implantação dos Recursos do PAC, efetuado pelo Observatório das Metrópoles - Núcleo de Maringá. Esse monitoramento entrevistou 218 moradores dos 246 lotes existentes no bairro. Por meio da análise comparativa desses dois momentos vividos por esses cidadãos que, após 31 anos, construíram suas vidas no bairro, criaram seus filhos, expandiram as moradias. Além disso, por conta da expansão da cidade, o bairro superou a precariedade dos anos iniciais e passou a despertar o interesse dos agentes imobiliários, já que atualmente é uma região propícia a investimentos suntuosos, como Condomínios Horizontais Fechados, entre outros. Corrêa (2004, p.26) explica-nos que a atuação do Estado visa criar condições de realização e reprodução da sociedade capitalista, ou seja, "condições que viabilizem o processo de acumulação e a reprodução das classes sociais e suas frações". Em Maringá isso fica bem visível nesse "Projeto de Requalificação Urbana e Social" que está sendo implantado no Conjunto Habitacional Santa Felicidade. O interesse mercantil das elites proprietárias e os acordos políticos falam mais alto do que os direitos daquelas 333 famílias residentes no bairro. 
As perguntas que ainda não conseguimos responder no final deste trabalho são: como é possível governar uma cidade como Maringá, quando tantos interesses diversificados se apresentam? E como contemplar a promoção social e a igualdade de cidadania em uma cidade (Figura 7 ) que foi erigida sobre a égide da cultura da classe média, do consumismo e da política conservadora que atende, prioritariamente, aos interesses dos agentes imobiliários? A resposta é certo dar-seá pelo coletivo, pelos explorados e marginalizados que estarão sempre lutando buscando espaços de resistência. A dialética das relações sociais no capitalismo constrói as saídas e as possibilidades.

FIGURA 7: VISTA DE MARINGÁ, COM DESTAQUE PARA A PRAÇA DA CATEDRAL - CIDADE QUE FOI ERIGIDA SOBRE A ÉGIDE DA CULTURA DA CLASSE MÉDIA, DO CONSUMISMO E DA POLÍTICA CONSERVADORA.

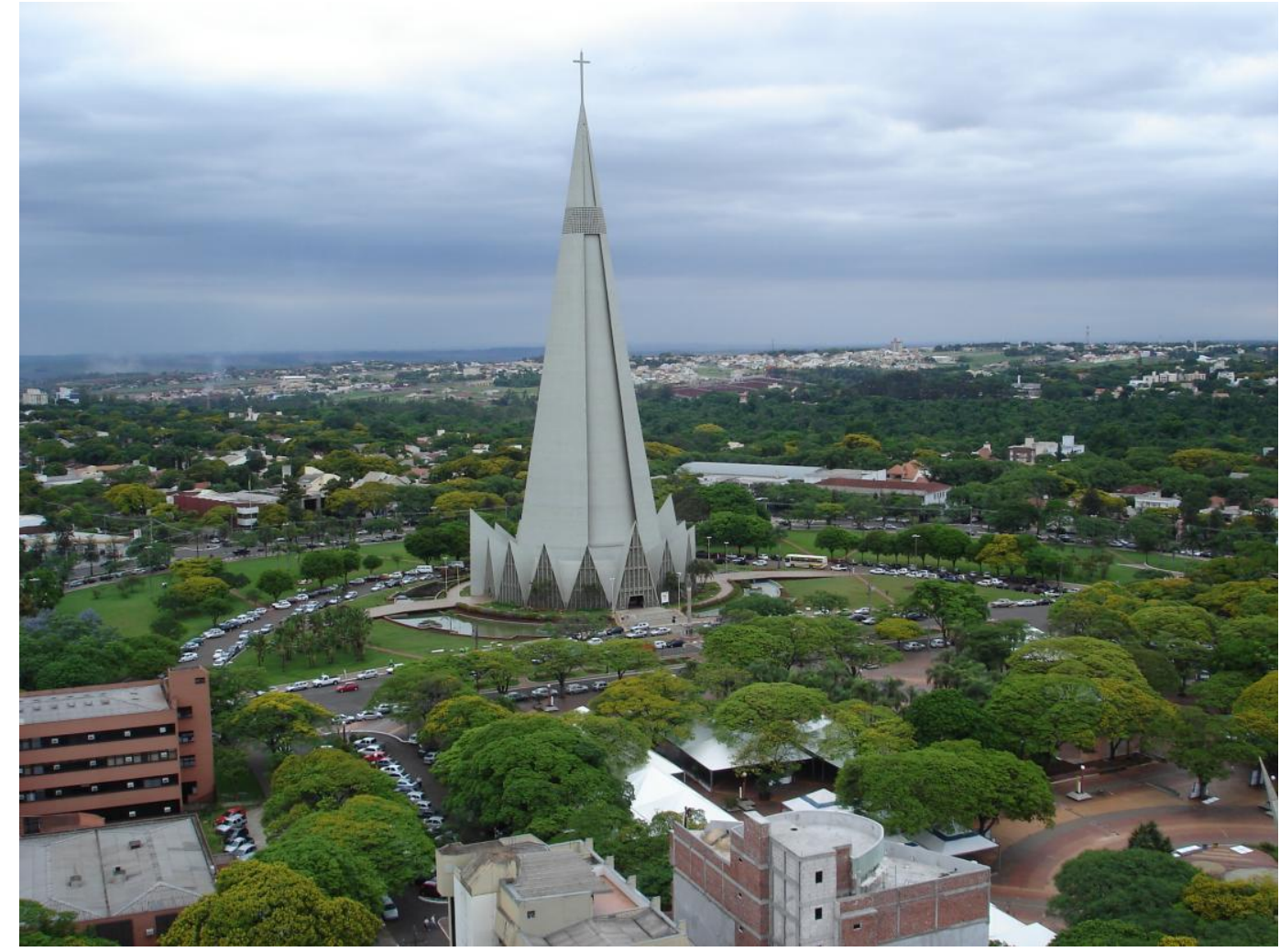

Fonte: acervo pessoal (Altair Aparecido Galvão) - outubro de 2007. 


\section{REFERÊNCIAS BIBLIOGRÁFICAS}

CANIATO, Ângela Maria Pires. A luta pela moradia de ex-favelados como parte essencial do processo de formação da consciência social. Dissertação (Mestrado em Psicologia Social) - Pontifícia Universidade Católica (PUC). São Paulo: 1986.

CORRÊA, Roberto Lobato. O espaço urbano. São Paulo: Editora Ática, 2004.

GALVÃO, Altair Aparecido. Condomínios Horizontais Fechados: segregadores ou segregados? Um estudo de caso no município de Maringá - Pr. Dissertação (Mestrado em Geografia) - Universidade Estadual de Maringá - UEM. Maringá - Pr, 2007.

MARICATO Ermínia. Metrópole na periferia do capitalismo. São Paulo: Hucitec, 1996.

MARTINS, José de Souza. O problema das migrações no limiar do terceiro milênio. In: O fenômeno migratório no limiar do terceiro milênio : Desafios Pastorais. CNBB (org.). Petrópolis - RJ: Editora Vozes, 1998.

MENDES, César Miranda; GRZEGORCZYK, Vanderlei. Centro, centralidades e verticalização em Maringá. In: MORO, Dalton Áureo (org). Maringá espaço e tempo: ensaio de geografia urbana. Maringá: UEM, pp. 89-126, 2003.

PASTERNAK, Suzana. Desenhando os espaços da pobreza. Cadernos de pesquisa do LAP. São Paulo: Fau/Usp, 2004.

PASTORE, José. Desigualdade e mobilidade social no Brasil. São Paulo: Edusp. 1979.

ROCHA, Márcio Mendes. A espacialidade das mobilidades humanas: um olhar para o norte central paranaense. Tese de Doutorado (Geografia). Universidade de São Paulo (USP), São Paulo, 1998.

ROCHA, Márcio Mendes. Mobilidade forçada - a economia política dos deslocamentos humanos. Acta Scientiarum, Maringá, Pr. V.21, no 1, 1999.

RODRIGUES, Ana Lúcia. A pobreza mora ao lado: segregação socioespacial na região metropolitana de Maringá. Tese (doutorado em Ciências Sociais) - PUC Pontifícia Universidade Católica de São Paulo, 2004.

RODRIGUES, Ana Lúcia. Uma análise da apropriação de instrumentos do estatuto da cidade pelo mercado imobiliário: projeto PAC ZEIS Santa Felicidade - Maringá - Pr. CD - III Seminário Nacional do Observatório das Metrópoles, p. 11-23, 2008.

SANTOS, Milton. Território e Sociedade: entrevista com Milton Santos. São Paulo: Fundação Perseu Abramo, 2000.

SCALON, Maria Celi. Mobilidade social no Brasil: padrões e tendências. Rio de Janeiro: luperj/Revan, 1999. 
TONELLA, Celene; RODRIGUES, Ana Lúcia. Metrópole regional no contexto da dinâmica paranaense. XXVII Encontro Nacional da ANPOCS. Caxambu - MG, 2003.

VAINER, Carlos B. A violência como fator migratório: silêncios teóricos e evidências históricas. In: Travessia: Revista do Migrante. São Paulo, no 25, p.0509, Mai-Ago, 1996.

ZALUAR, Alba; ALVITO, Marcos. Um século de favela. Rio de Janeiro: FGV, 1998.

(Recebido em outubro/2009. Aceito em fevereiro/2010) 